\title{
Application of Cloud Technology in the Management of Electronic Payslips-Brunei Case Study
}

\author{
H. A. S. Siti Noorfatimah, H. M. J. Norhuraizah, S. Suresh, and B. M. B. Nurafiqah
}

\begin{abstract}
In any organization, the payroll covers a sum of financial records on salaries, wages, bonuses and deductions of employees. In essence the payroll refers to the amount paid to all employees for the services they have provided to the organisation for a certain period of time. In the payroll an important constituent element is the Pay slip and this is the notification document for an employee on the direct deposit transaction that has been made and this normally includes details on gross salary, taxes, deductions and so forth. The significance of having a computerized payroll system with the issue of electronic pay slip is rising progressively since it ensures the delivery of a timely, efficient and accurate payroll at each pay dates. Towards automating the generation and processing of payroll through electronic pay slips, organizations started to divert to the use of Software controlled computerized payroll system like PeopleSoft and so forth. While some payroll system offers inherent electronic pay slip feature, the application is often still hosted in the traditional way in the computer which essentially requires expensive physical hosting infrastructures and operating expenditures. The emergence of cloud computing technology now provides the ability of hosting a large scale computation and data storage achieved through virtualization with high expansibility, reliability and low price service. So taking the issues in the use of electronic pay slip (e-payslip) and the benefits of cloud computing, a Cloud based electronic pay slip management and generation application using Luna Cloud has been proposed in this paper.
\end{abstract}

Index Terms -Payroll, cloud, e-payslip, lunacloud

\section{INTRODUCTION}

In any organization, the payroll covers a sum of financial records on salaries, wages, bonuses and deductions of employees. In essence the payroll refers to the amount paid to all employees for the services they have provided to the organization for a certain period of time. In the payroll an important constituent element is the Pay slip and this is the notification document for an employee on the direct deposit transaction that has been made and this normally includes details on gross salary, taxes, deductions and so forth So this processing of pay slip - its generation and management can be one of the most complex tasks [1]. It requires a multitude of skills and knowledge in the areas of payroll administration, human resources, finance, and application of technology as well as the management. Although organizations derive no competitive advantages from payroll activities, the function is still critical to business operations

The traditional payroll management system saw the manual

Manuscript received November 5, 2013; revised March 19, 2014.

The authors are with the Institut Teknologi Brunei, Brunei Darussalam (e-mail: $\quad$ fatimah.safar@itb.edu.bn; norhuraizah.jaafar@itb.edu.bn; suresh.sn@itb.edu.bn; afiqah.basheer@hotmail.com). system with the entire payroll processes done completely by hand involving pen and ink, adding machines and manual spreadsheets instead of using computers, software and other aids leaving a lot of room for payroll errors. This process includes all the laborious, tedious and time consuming administration work also.

To alleviate this complex and repetitive tasks while following the manual payroll processes, many organizations have diverted to the use of a computerized payroll management system. The system is tailored for the payroll department to input the employee's entire payroll related data easily and efficiently into the system. The system also automates the tedious payroll calculations thus eliminating the errors arising from manual arithmetic calculations. In addition, necessary pay slips can also be generated at the convenience of a mouse click.

Although a computerized payroll system is widely used in several organizations in many countries including Brunei, still many organizations produce the traditional paper-based pay slips to be distributed to their employees every month. This requires the employers to allocate a considerable amount of money every month in order to be spent on the preparation and production of these paper-based pay slips. Carbon emissions from overworked printers and sealers means that paper-based pay slips is not an efficient and environmentally friendly option.

Some organizations have considered introducing electronic pay slips to their employees instead of having a payroll management system tailored for the purpose of payroll processing only. With electronic pay slips, there will be no more delay in receiving the pay slips as it will be available to the employees a day or two before the actual payday. In addition, employees can access, download and print their current and historical pay slips by themselves, thus greatly removing the burden of the payroll department. This application which is often hosted as web-based applications requires the expensive and complex computing infrastructure and resources such as servers and storages, memory, CPU cycles and network equipment to be physically owned and maintained by the organization.

As Payroll processing is considered as a data-driven process; the next logical step is to move to cloud-based payroll management system. There has been a considerably huge transition in the concept of distributed computing to grid computing and recently, to cloud computing. Cloud Computing has recently emerged as a new paradigm for hosting and delivering services over the internet [2]-[6] where data and programs are being swept up from desktop PCs and corporate server rooms and installed in "the compute cloud" [2]-[6]. Users of cloud computing are said to be working "in 
the cloud", where they can access computer services, such as data storage and productivity software stored in remote server by using a computer with Internet access and browser software [2]-[6].

Thus, in order to overcome all the problems that have been identified above in the management of electronic pay slip and benefits the cloud computing offer, this proposed research presented in the paper aims towards developing an application for a payroll management system that is hosted in the cloud Server called Cloud based e-Payslip. With the innovation of cloud computing technology, e-Payslip will be hosted based on the Infrastructure-as-a-service model of the cloud computing, thus changing the traditional way payroll applications are normally hosted. With IaaS [2]-[6], the infrastructures such as the networks, servers, storages and other fundamental resources are provided by the service provider. Here, the operating systems or applications can be run on top of the infrastructures leaving the user with complete control of the software. Maintenance of these computing infrastructures will be under the responsibilities of the service provider and since the application is hosted on server clusters and not limited to a single server data that are backed up at all times regardless of system failures or downtime. In essence the electronic payslips can be accessed by employees at their convenience from mobile or computer thereby eliminating need to print pay slips and distribute to employees and also managing/ upgrading of physical infrastructure towards electronic payslip. The rest of paper is organized as follows. Section II talks on Electronic payslips and the Cloud Technology. Section III talks on the proposed architecture of Cloud based electronic pay slip management system followed by the algorithm used. Section IV talks on implementation of the cloud based electronic payslip management system using Luna cloud. Section V is concluding section with future work.

\section{PROCEDURE FOR PAPER SUBMISSION}

\section{A. TAFIS (Treasury Accounting and Financial Information System) in Brunei}

The Brunei government manages the daily-rated employees' payrolls by using one of the modules available in TAFIS (Treasury Accounting and Financial Information System) called the DRP (Daily-Rated Payroll) module. Although TAFIS is a computerized system and it automates all of the processes involved in payroll processing and pay slip production, it still produces only the traditional paper-based pay slips to be distributed to the government employees. The government still has to spend a huge amount of money and time on the preparation and production of these paper based pay slips. This often results in the pay slip to arrive late to the employees. Producing paper-based pay slip is not environmentally friendly as it produces carbon emissions, overworked printers and sealers. Currently, pay slips for the daily-rated government employees are being printed only upon request which makes it troublesome for the employees to repetitively make requests to the payroll department to handle such requests. Furthermore, it is also difficult for the employees to view their historical pay slips, if there is a need for reference in the future, in case they are lost. TAFIS essentially requires a redundant and expensive physical hosting, which includes servers, storages, and other physical infrastructures and computing resources. It must be fully equipped so that it can be used in accordance with the web-based application. With the increasing number of new government employees, the capacities of the physical infrastructure may also to be increased which in turn may require more investments from the government. It is better that the application be physically installed on the user's machine and accessing done.

\section{B. Sistem e-Penyata Gaji and Laporan}

Since 2010, the government employees in Malaysia can access their pay slips online using a system called "e-Penyata Gaji \& Laporan". With the implementation of the system, the Malaysian government has effectively saved the costs that came up from the preparation, production and posting of paper-based pay slips. The downside of the "Sistem e-Penyata Gaji \& Laporan" system is that it has to cater the access for millions of government's employees in Malaysia. The efficiency and performance of the system are affected whenever large amount of concurrent users tried to access the system at the same time especially during the actual pay day. In this case, the website will need to handle, a significantly heavy traffic, giving a negative impact on user's experience on the system. This problem will get worse as the number of employee increases, requiring the government to invest more on buying or upgrading the capacities of the servers and other computing resources in order to keep the system up and running at its maximum performance.

In addition to the above mentioned payroll management software, there are organizations which use PeopleSoft package towards generating electronic pay slips and other related payroll management jobs. But still the issue of maintaining or upgrading physical infrastructure like servers and other computing resources like processing power is a challenge.

\section{Cloud Computing Technology}

Cloud computing technology can be described as a model for enabling convenient, on-demand network access to a shared pool of configurable computing resources (e.g., networks, servers, storage, applications, and services) that can be rapidly provisioned and released with minimal management effort or service provider interaction [2]-[6]. In a simpler term, it can be described as a type of internet-based computing where different resources such as servers, storages and applications are delivered to an organization's computers and devices through the internet instead of the computer's hard drives.

The three of the most accepted categories of cloud computing models are Software as a Service (SaaS), Platform as a Service (PaaS) and Infrastructure as a Service (IaaS). SaaS model of the cloud computing technology is where applications are provided to the user through a web browser or any thin-client interface without the need for the user to know or manage the underlying infrastructure on which the application is running [2]-[6]. The SaaS model can also be regarded as web-delivered software. PaaS model of the cloud 
computing technology is where consumer deploys and controls their applications on the cloud where it offers full or partial application development that users can access [2]-[6]. In this case, user only controls the applications but not the network, servers, operating systems or storage. IaaS model, which is one of the three most accepted models can generally be described as a model where consumer rent the basic computing resources such as storages and network capacities from the service provider but at the same time will be able to manage the operating systems, applications, storages and network connectivity independently.

There are primarily four cloud deployment models which have been recommended by the National Institute of Standards and Technology (NIST) namely the Private Cloud, Public Cloud, Hybrid Cloud and the Community Cloud [2]-[6].

So taking the issues discussed in the generation of Electronic payslip and the advantages that the use of Cloud computing would offer, we here have proposed an IaaS based Cloud payroll management system towards generating electronic payslip. The proposed system would also allow employees in the organization to access their pay slips electronically via internet from their desktop or their mobile. This scheme would be putting an end to the issues discussed on printing and distributing pay slips to employees of organizations and also towards managing the physical infrastructure like server storage, memory, processing power etc in terms of maintenance, upgrading based on number of employees, any disaster etc. In the application proposed, the complete control of software and employee details however, lies with the organization hosting it on cloud server as they rent only the infrastructure like processing power and the server power towards hosting the electronic payslip system. The details are presented in the next section

\section{Cloud Based Payroll Management Systems- ELECTRONIC PAYSLIPS}

Electronic Payslip is a cloud-based payroll management system used to manage daily rated government employee's payroll calculation and pay slips generation. It is also used to provide to the employees access to their pay slips electronically via the internet through the web browser. This is achieved through the adoption of the IaaS model of the cloud computing technology. The service provider chosen for hosting e-Payslip is Lunacloud, making use of their cloud server services. In this case, the infrastructures that are required in order to host e-Payslip such as the networks, servers, storages and other fundamental resources are provided and maintained by the service provider leaving the organization with complete control of the software or application. In addition, their operating systems and applications can be run on top of these infrastructures independently.

Hosting the application using Lunacloud cloud server enables the underlying infrastructure such as RAM, CPU or storage arrays to be managed by the service provider, but the organization will be free to choose any mix of RAM (512 MB to $96 \mathrm{~GB})$, vCPU (1-8) and Disk (10 GB to $2 \mathrm{~TB}$ ) and any popular Linux distribution (CentOS, Debian, Ubuntu, Red Hat, Fedora, SUSE, OpenSUSE) or Windows Server 2008. The cloud server will be online which can be powered on or off, resized, scaled up or down on the fly and controlled simply from their web control panel without the need to reboot the server. These infrastructures and computing resources are highly scalable where organization will only have to pay for the services that they are using.. Cloud computing technology uses the real cloud as a metaphor, where one can store and edit files which are located at an off-site server, perform a wide variety of IT tasks and are being able to access it anytime and anywhere using a web browser as long as there is an Internet connection [3]-[5].

Cloud based Payroll Management involving Electronic payslip consist of two main components namely the administration side and the user side which are explained below.

\section{A. Administration Side}

The administration side of e-Payslip is used to automate the daily rated employee's payroll calculation and pay slips generation. There are four access levels for the administration side of e-Payslip namely the Administrator, Verifier, Approver and Authorizer. The process flow details for the admin side of e-Payslip would be as follows:

- Administrators for each unit of the departments need to do the necessary setup or configurations.

- Once the setup is done, Administrator can enter or update employee's individual allowances or deductions at the Earnings \& Deductions screen

- Verifier will have to review the details entered by the administrator at the Earnings \& Deductions screen.

1) If all the details entered are correct, the verifier can change the corresponding status to 'Verified'

2) Otherwise, Administrator will have to recheck and update the details entered.

- Once the status is changed to 'Verified', Approver will have to review the details verified by the verifier at the Earnings \& Deductions screen.

1) If all the details entered are correct then approver can change the corresponding status to 'Approved'

2) Otherwise, the verifier will have to re-verify the details.

- Once the status is changed to 'Approved', Administrator can now create or enter the departmental timesheet details at the Time Report screen.

1) This screen is used by the administrator to add employee's attendance and adjustments details. The employee's pay details will then be automatically calculated and populated based on the details entered

- Verifier will have to review the details entered by the Administrator at the Time Report screen.

1) If the details entered are correct, then the Verifier can change the corresponding status to 'Verified'

2) Otherwise, the Administrator will have to review and update the details entered.

- Once 'Verified', Approver will have to review the details verified by the verifier at the Time Report Screen.

1) If the details are correct, then the Approver can change the status to 'Approved'

2) Otherwise, the Verifier will have to re-verify the details 
at the Time Report Screen.

- Once 'Approved', the Authorizer will have to review the details approved by the Approver at the Time Report Screen.

1) If the details are correct, then the Authorizer can change the corresponding status to 'Authorized'

2) Otherwise, the Approver will have to review the details at the Time Report screen.

- Once the status at the Time Report screen has been changed to Authorized, pay slips will be generated and the payroll process is now completed.

\section{B. User Side}

The user side of e-Payslip is used to provide employees a round-the-clock access to logon to their pay slips electronically. It is accessible by all authorized official government employees. The process flow details for the user side of the system would be as follows:

- At the login screen, system will determine whether the user has registered with the system.

- If no, users will have to register at the registration screen first.

- If registration is successful, then users will be directed to the registration successful screen where user can click on a link to return to the login screen.

- Otherwise, an error message will appear at the registration screen and users have to re-register.

- If yes, i.e, if the Registration is successful, then users will be directed to the home screen.

- Users will then have a choice to either search or view the pay slips as well as to download or print the PDF version of the pay slips.

\section{IMPLEMENTATION USING LUNA CLOUD}

The implementation of the above proposed cloud based payroll towards electronic payslip viewing and printing has been validated using Luna Cloud system. In this case the infrastructure such as memory, server, processing power etc., has been accessed as service thereby hosting the payroll system on top of infrastructure by organization. The maintenance of the infrastructure is managed by Luna Cloud service provider and software is fully controlled by the owner organization. The Electronic pay slip system hosted for validation on cloud has got two parts- i) User side for viewing pay slip and ii) Administrator side for generation which requires quite an amount of approval and as such this would be shown now as screenshots.

In respect of the administration side, there are four access levels for administering the e-payslip and there are the administrator, the verifier, the approver and the authorizer which are available for selection on the home screen page. The users from the administration side however, initially have to login using their username and password in order to go to the home screen which is for security purposes as different level have their own different role. In the home screen, there are menu available such as Set up, Earning and deduction, Time report, Job data, Pay slip. Within this menus, there are also sub menu available in order to fulfill the tasks of the administrator.
The administrator will be able to add, edit and delete new or existing earning codes details accordingly based on the available data provided, which is the department ID and also the Location ID as shown in Fig. 1. Administrator may also add and make changes of the deduction codes details from the Set Up menu under the deduction screen. The detail needed for the revision of earning and a deduction is suitable of the arrangement made is as shown in Fig. 2.

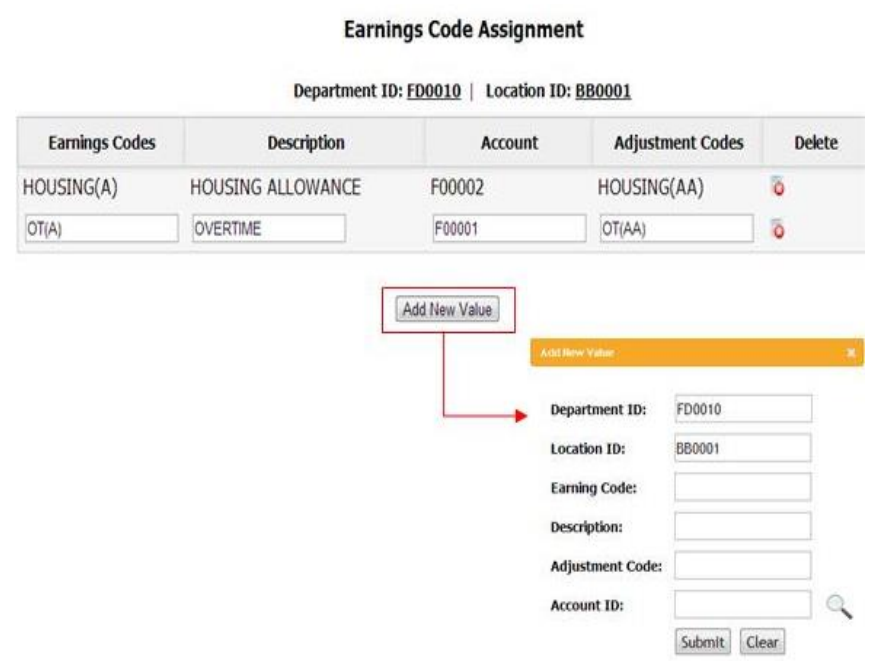

Fig. 1. Set up: earnings screen.

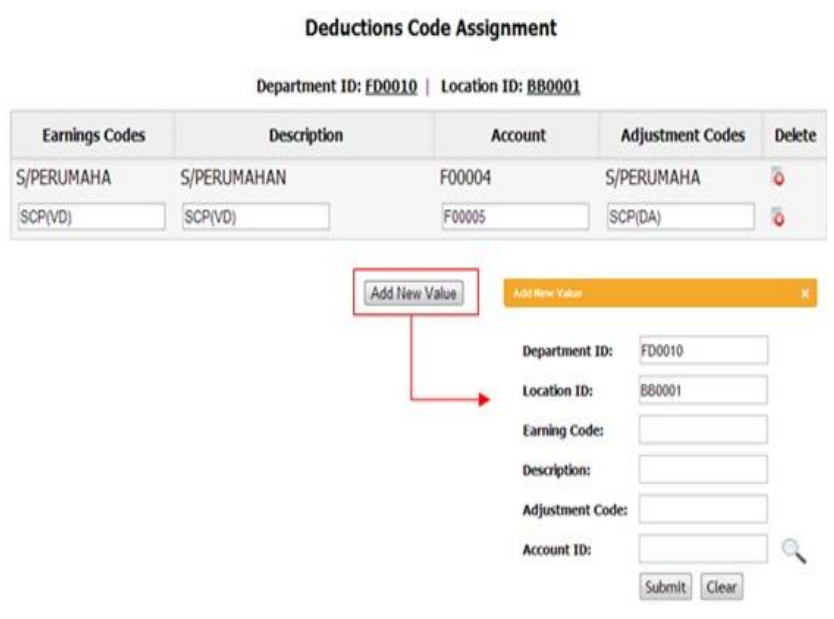

Fig. 2. Set up: deductions screen.

The account and budget screen will be available from the set up menu. From the account and budget screen, administrator will be able to make changes in the account budget details as felt necessary. It is used to determine from which budget year and accounts the allowances are coming from and to which accounts the deductions are going into, as shown in Fig. 3.

From the ESH and HCL screen, the administrator can make changes of the ESH and HCL values details such as adding, editing and deleting the new or the existing values. As ESH and HCL are included in the pay slip every month, the amount would differ per individual depending on the division, as shown in Fig. 4.

From the menu of Earning and deductions, the available sub menu is used for searching the existing value by entering Employee ID, Department ID and also Location ID. The fields of the employee ID help to search the employee according to the department and from which district they are 
positioned. By searching the employee ID, there will be no redundancy and unavailable results indicated as shown in Fig. 5 .

\section{Account, Budget Assignment}

Department ID: FD0010 | Location ID: BB0001

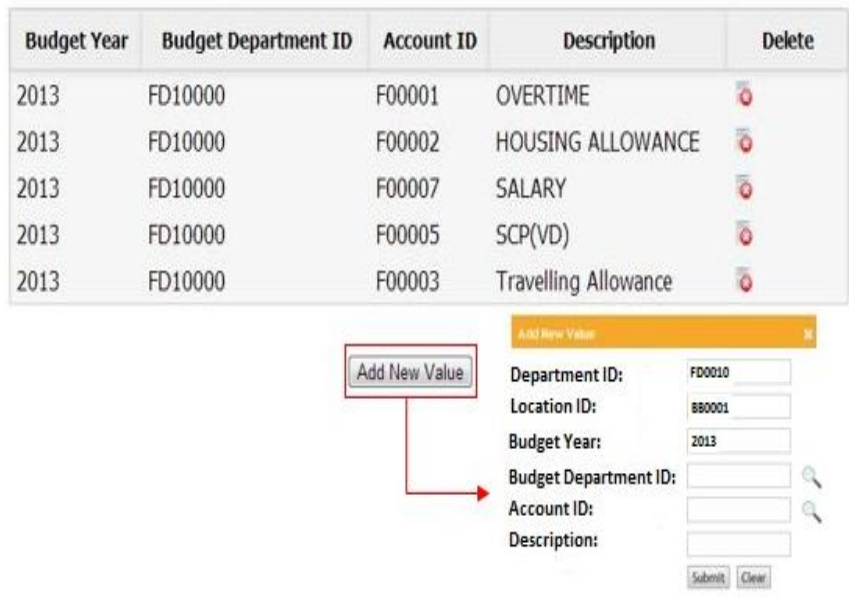

Fig. 3. Set up: account, budget screen.

ESH and HCL Assignment

\begin{tabular}{|c|c|c|c|}
\hline \multicolumn{4}{|c|}{ ocation ID: FD0010 } \\
\hline Divisions & Elaun Sara Hidup & Elaun Kurnia Khas & Delete \\
\hline 1 & 80.00 & 0.00 & $\overline{0}$ \\
\hline 2 & 100.00 & 150.00 & $\overline{0}$ \\
\hline 3 & 120.00 & 170.00 & $\overline{6}$ \\
\hline 4 & 170.00 & 200.00 & $\overline{0}$ \\
\hline 5 & 170.00 & 200.00 & $\overline{0}$ \\
\hline
\end{tabular}

Add New Value

Fig. 4. Set up: ESH and HCL screen.

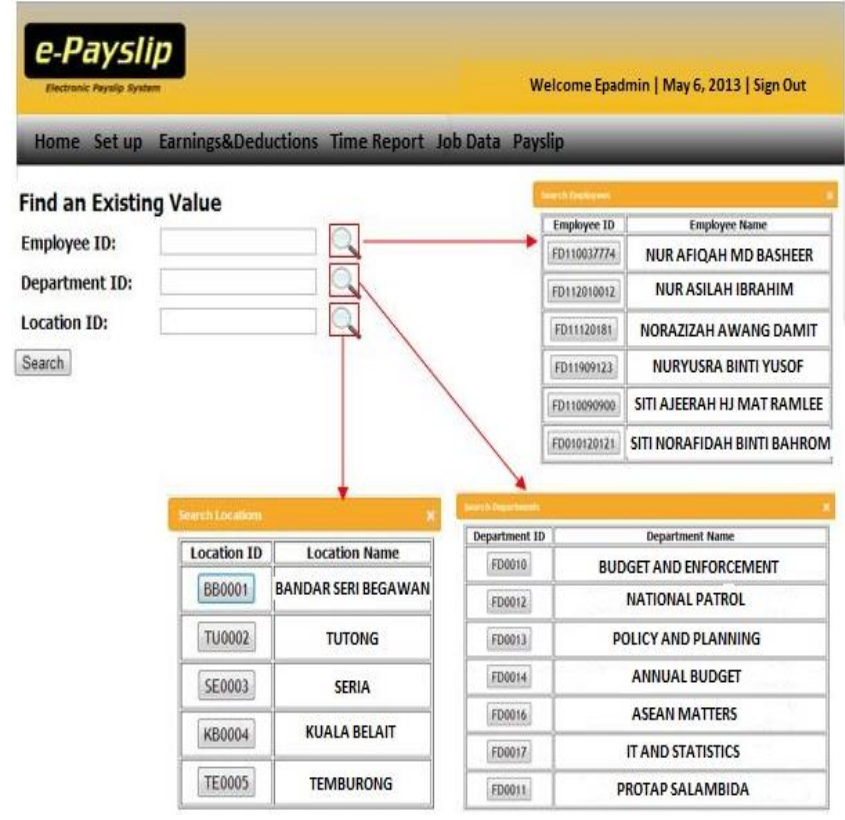

Fig. 5. Find earning and deductions.

The sub menu available in the earning and deduction is used by the verifier to verify details entered by the administrator and it is also used by the approver to approve the details verified by the verifier. The sequence of having this activity is to show to the verifier and approver the data which has been entered by the administrator.

In the Time Report menu, Administrator will be able to make changes such as adding, editing and deleting the departmental time reports details. As the data like Department ID, Account ID, Location ID, year and Month, Budget department ID, Payment Location ID and Timesheet Status entered in the needed relevant fields, then the department timesheet information accordingly gets created depending on the tasks of the administrator as shown in Fig. 6.

Department Timesheet Information

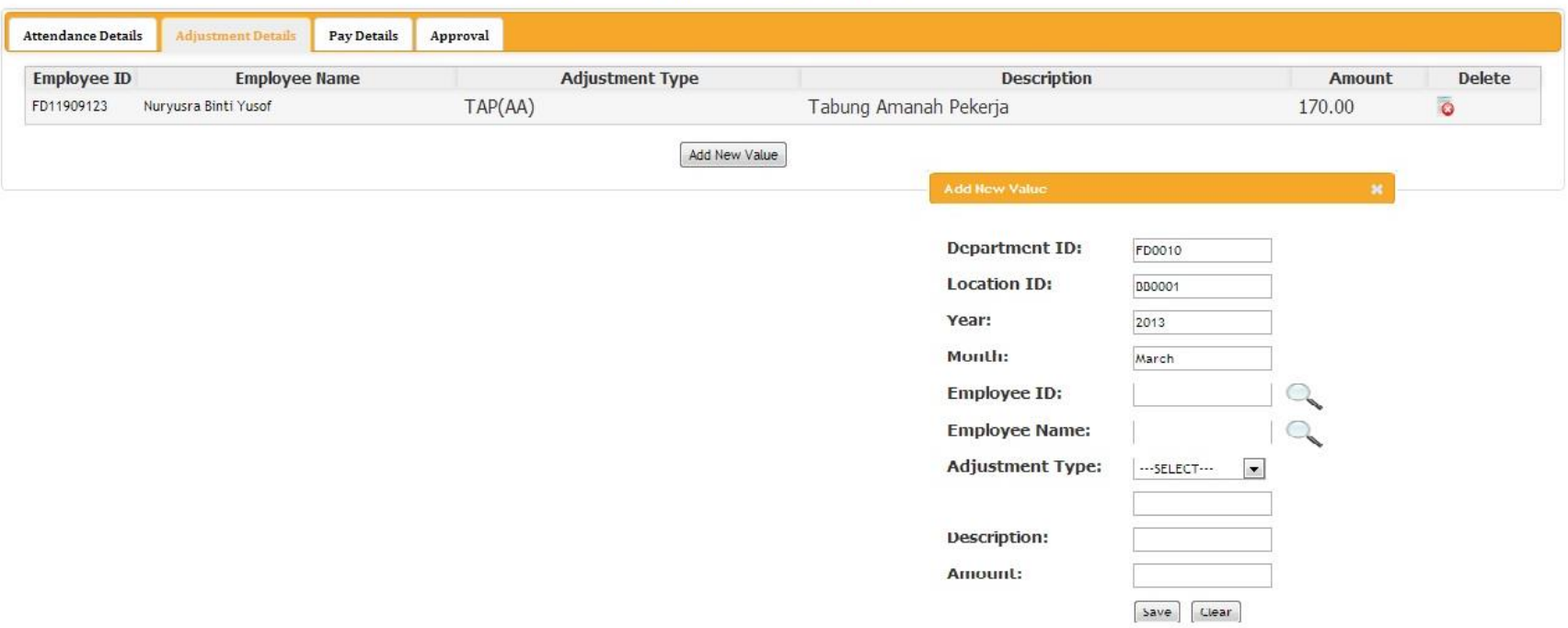

Fig. 6. Time report screen (administrator).

In the Department Timesheet report, verifier can verify the departmental time report details which are entered by the administrator. Lastly, the approver can approve the departmental time report details as verified by the verifier. Authorizer can then authorize the departmental timesheet details which are approved by the approver. Once it is authorized, the pay slips can be generated as shown in Fig. 7. The Administrator will then be able to print the pay slips for the employees as well as changing employees existing job data well as changing employees existing job data. 


\section{Department Timesheet Information}

\begin{tabular}{|c|c|c|c|c|c|c|c|c|c|c|c|c|c|c|c|c|}
\hline Attendance Details & Adjustment Det & & Details & Approv & & & & & & & & & & & & \\
\hline Employee ID & Employee Name & $\begin{array}{c}\text { Days } \\
\text { Worked }\end{array}$ & Rates & $\begin{array}{c}\text { Total } \\
\text { Wages }\end{array}$ & $\begin{array}{c}\text { Total } \\
\text { Adjustments }\end{array}$ & $\operatorname{ESH}(A)$ & $\mathrm{HCL}(\mathrm{A})$ & ESH(D) & $\operatorname{TAP}(D)$ & $\operatorname{SCP}(D)$ & $\operatorname{TAP}(\mathrm{C})$ & $\operatorname{SCP}(\mathrm{C})$ & $\begin{array}{l}\text { TOP- } \\
\text { UP(C) }\end{array}$ & $\begin{array}{l}\text { Other } \\
\text { Earnings }\end{array}$ & $\begin{array}{c}\text { Other } \\
\text { Deductions }\end{array}$ & $\begin{array}{l}\text { Net } \\
\text { Pay }\end{array}$ \\
\hline FD112010012 & $\begin{array}{l}\text { NUR ASILAH BINTI } \\
\text { IBRAHIM }\end{array}$ & 21 & 150.00 & 3150.00 & 0.00 & 120.00 & 170.00 & 30.00 & 157.50 & 98.00 & 157.50 & 98.00 & 0.00 & 0.00 & 0.00 & 3154.50 \\
\hline FD11120181 & $\begin{array}{l}\text { NORAZIZAH BINTI } \\
\text { AWANG DAMIT }\end{array}$ & 22 & 200.00 & 4400.00 & 0.00 & 100.00 & 150.00 & 25.00 & 220.00 & 98.00 & 220.00 & 98.00 & 0.00 & 0.00 & 0.00 & 4307.00 \\
\hline FD110037774 & $\begin{array}{l}\text { NUR AFIQAH BINTI } \\
\text { MOHD BASHEER }\end{array}$ & 22 & 300.00 & 6600.00 & 0.00 & 80.00 & 0.00 & 20.00 & 330.00 & 98.00 & 330.00 & 98.00 & 0.00 & 200.00 & 98.00 & 6334.00 \\
\hline FD110090900 & $\begin{array}{l}\text { SITI NUR AUEERAH } \\
\text { BINTI HJ MAT } \\
\text { RAMLEE }\end{array}$ & 23 & 18.00 & 414.00 & 0.00 & 170.00 & 200.00 & 42.50 & 20.70 & 14.49 & 20.70 & 17.50 & 3.01 & 0.00 & 0.00 & 706.31 \\
\hline FD11909123 & $\begin{array}{l}\text { NURYUSRA BINTI } \\
\text { YUSOF }\end{array}$ & 19 & 10.00 & 190.00 & 170.00 & 170.00 & 200.00 & 42.50 & 9.50 & 6.65 & 9.50 & 17.50 & 10.85 & 0.00 & 0.00 & 501.35 \\
\hline
\end{tabular}

Fig. 7. Time report screen: pay details tab (administrator, verifier, approver and authorizer).

We have seen so far as how different sections of Payroll is responsible in generating payslips for employee which takes into account number of hours, job and so forth. Now we would see as how employees of the organization are able to access the payslip electronically from cloud for viewing on their mobile or computer as appropriate.

To start with the employees of organization would log in with their credentials to access the payslips as shown in Fig. 8. System here would determine if they have been registered users or not. If not registered, employees need to register. Once registration is successful, they are directed to screen which gives link to return to Login screen for accessing payslips. If registration is not successful, an error message displayed. On successful registration, registered users of organization can access pay slip by entering the year and month. Based on the details entered, payslip displayed to user which gives option to user to download format and print it too as shown in Fig. 9.

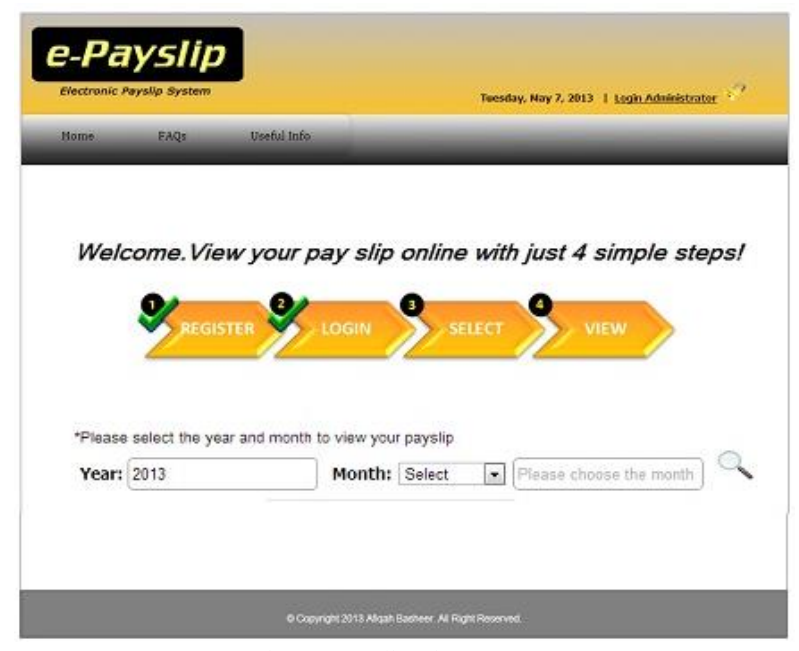

Fig. 8. Payslip view screen.

So from results it is clear that organization can deploy electronic payslip generation at cloud server by accessing infrastructure like Server, CPU, RAM and so. Software is fully managed and controlled by organization locally and hosted above the cloud infrastructure. The maintenance of infrastructure is done by cloud service provider and control of software by organization. This way organization is not spending money on upgrading and maintenance of infrastructure as these are done by cloud service provider.
Organization only pays for access of service only and takes care of maintenance of software only. Users need to register with the system for accessing payslip electronically from cloud server which can be done from their mobile handset or computer as appropriate.

$\begin{array}{ll}\text { NO. KAKITANGAN: FD110037774 } & \text { TARIKH: 22-MAC-2013 } \\ \text { NO. KAD PENGENALAN: } 01037774 & \text { CARA PEMBAYARAN: EFT } \\ \text { NAMA: NUR AFIQAH MD BASHEER } & \text { BANK: BIBD } \\ \text { JABATAN: FORESTRY DEPARTMENT } & \text { NO. AKAUN: FOO37774 } \\ \text { LOKASI: BANDAR SERI BEGAWAN } & \text { NO. SIRI: } 5\end{array}$

\begin{tabular}{|l|l|l|l|}
\hline \multicolumn{1}{|c|}{ BAYARAN } & \multicolumn{2}{c}{ POTONGAN } \\
\hline GAJI & 6600.00 & POTONGAN TAP & 330.00 \\
\hline ELAUN KURNIA KHAS & 0.00 & ESH 25\% & 20.00 \\
\hline $\begin{array}{l}\text { ESH } \\
\text { HOUSING ALLOWANCE }\end{array}$ & $\mathbf{8 0 . 0 0}$ & SCP & 98.00 \\
\hline TOTAL ALLOWANCES & $\mathbf{6 8 8 0 . 0 0}$ & TOTAL DEDUCTIONS & $\mathbf{4 4 8 . 0 0}$ \\
\hline & & & \\
\hline JUMLAH BAYARAN GAJI: 6432.00 & \\
\hline
\end{tabular}

Fig. 9. Electronic payslip.

\section{CONCLUSION AND FUTURE WORK}

In conclusion, it can be seen that user's confidence and interest in cloud computing services as well as their demand for it has increased significantly over the past few years. Implementing the electronic payroll system alone has proven to benefit both employees and employers in many organizations. Deploying it in the cloud will shift the entire payroll world into a whole new paradigm, together adding more values and advantages to business operations. With cloud-based hosting, costs can significantly be reduced since the flexibility in deployment that it enable users to pay only for the services that they are using as opposed to traditional hosting. The Cloud Service also offers a better maintenance and backup service which is an important part of an 
organization's disaster recovery planning. Thus, industries may start to consider using the cloud computing technology and migrate away from physical IT platform towards internet based services as a way out for similar hardware, infrastructure and software needs.

The system got lot of scope for future enhancement like including the calculation for the annual bonus, generation of all reports related to employees, attendances, leaves, or payment details which can be printed and also Email notifications sent to employees to inform them about the availability of their pay slips. The system in future also need to include more employee self-service features to the user's side of the system such as applying leave online and also carry out system testing to find out user's acceptance on the system. In addition to this service for electronic pay slip, there is a need for strong security measure at the cloud server towards accessing from cloud by organization and the user. For such system to function there needs to be proper and reliable network connectivity which has effectively managed too.

\section{REFERENCES}

[1] T. Sandersfeld. How to choose payroll systems: manual, software, external. [Online]. Available: http://www.howtodothings.com/business/a3975-how-to-choose-payro 1l-systems.html

[2] Q. Zhang, L. Cheng, and R. Boutaba, "Cloud computing: state-of-the-art and research challenges," Journal of Internet Service Applications, vol. 1, no. 1, pp. 7-18, May 2010.

[3] P. Gupta and S. Gupta, "Mobile cloud computing: the future of cloud," International Journal of Advanced Research in Electrical, Electronics and Instrumentation Engineering, vol. 1, no. 3, pp. 134-145, September 2012.

[4] N. Fernando, S. W. Loke, and W. Rahayu, "Mobile cloud computing: a survey," International Journal of Future Generation for Computer Systems, vol. 29, no. 1, pp. 84-106, January 2013.

[5] B. Q. Cao, B. Li, and Q. M. Xia, "A service-oriented qos-assured and multi-agent cloud computing architecture," in Proc. First International Conference CloudCom, Beijing, China, 2009, pp. 644-649.

[6] D. Talia, "Cloud meet agents: towards intelligent cloud services," IEEE Internet Computing, vol. 16, no. 2, pp. 78-81, March-April 2012.

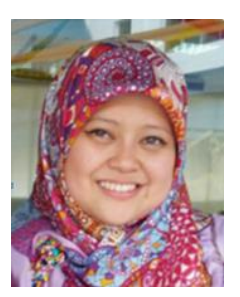

H. A. S. Siti Noorfatimah is a graduate from the University of East Anglia, UK in strategic information system. She completed her degree in business administration specializing in business information system from the University of Brunei Darussalam. She started her career working as a human resource officer in Civil Service Department in Brunei Darussalam. She is currently working as a lecturer at the Institut Teknologi. Her research interests are mainly in information systems, cloud computing.

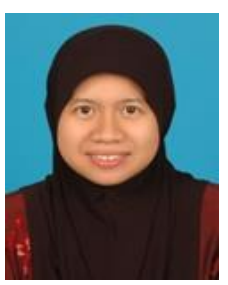

H. M. J. Norhuraizah holds bachelor's degree in electronic commerce from Edith Cowan University, Australia and postgraduate diploma in teaching education from University of Brunei Darussalam. She is currently pursuing master's degree in internet \& web computing from RMIT University, Australia. She has worked in past as an assistant manager in Jabatan Telekom Brunei and education assistant in IDP Education in Brunei. She is currently working as a lecturer in computing and information systems, Institut Teknologi Brunei. Her research interests are mainly on electronic commerce, multimedia, internet computing and information technology fundamentals.

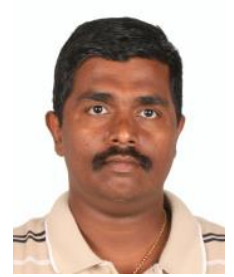

S. Suresh is an associate professor in the Department of Computer and Information Systems, Institute of Technology, Brunei. He is also a senior member of IEEE computer Society and Computer Society of India too.

He has supervised more than 30 research students leading to M.Sc, ME, M.Phil and M.S degrees and currently supervising 3 students leading to M.Phil and $\mathrm{Ph} . \mathrm{D}$ in UWI, Jamaica and a doctoral student in Institut Teknologi Brunei respectively. He has got to his credit, as on date, more than 60 fully refereed research papers published in the proceedings of major IEEE international conferences, as book chapters and in international journals. He is also a reviewer and technical committee member for a number of IEEE conferences and journals. He has conducted many tutorials, workshops and also given guest lectures in networking in various Universities and Colleges. His current research interests are mainly towards 'mobile and ubiquitous computing - wireless sensor networks, RFID, cloud computing, mobile intelligent agents' used in the health, commercial and engineering sectors.

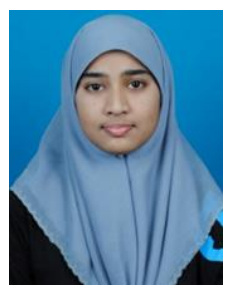

M. B. Nur Afiqah holds bachelor's (HONS) in internet computing from computing and information systems, Institut Teknologi Brunei, Brunei Darussalam in 2013. Her final year research project was on cloud computing technology towards electronic payslip. Her research interest is more on cloud computing. 